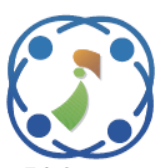

\title{
Comparative Study of the Three Models (ANN-PMC), (DWT-ANN-PMC) and (MLR) for Prediction of the Groundwater Level of the Surface Water Table in the Saïss Plain (North of Morocco)
}

\author{
Abdelhamid El Ibrahimi ${ }^{1 *}$ Abdennasser Baali ${ }^{1}$ Amine Couscous ${ }^{1}$ \\ Touria El Kamel ${ }^{1}$ Nadia Hamdani $^{1}$ \\ ${ }^{1}$ Sidi Mohamed Ben Abdellah University, Laboratory of Geosystems, Environment and Sustainable Development, \\ Faculty of Sciences dher el mahrez, Fes, Morocco \\ * Corresponding author's Email: abdelhamidsvt@gmail.com
}

\begin{abstract}
A new method based on the coupling of discrete wavelets (DWT) and artificial neural networks with perceptron multilayers (ANN-PMC) is proposed to predict the groundwater level. The relative performance of the DWT-ANN-PMC model has been regularly compared to artificial neural network (ANN-PMC) and multiple linear regression (MLR) models. Precipitation, temperature and average groundwater level are the variables introduced to explain and validate the models, with a monthly time step for the period March 1980 to March 2014 at two sites in the Plain of Saïss. The results of the study indicate the potential of DWT-ANN-PMC models in the prediction of groundwater levels. The forecast results indicate that the coupled wavelet neural network (WN) models were the best models for forecasting SPI values over multiple lead times in the Saïss Plain. It is recommended that further studies should explore this proposed methodology, which may in turn be used to facilitate the development and implementation of more effective strategies for the sustainable management of groundwater.
\end{abstract}

Keywords: Artificial neural networks, ANN-PMC, DWT-ANN-PMC, Ground water level, MLR, The Plain of Saïss.

\section{Introduction}

Sustainable management of groundwater resources in conjunction with surface waters in a watershed is very important to ensure the sustainability of a surface and groundwater resource pool [1]. A reliable forecast of groundwater levels is an essential parameter in the planning and implementation of groundwater the precise prediction of groundwater levels is essential for sustainable use and management of essential groundwater resources. Given that groundwater is hidden and that groundwater has great temporal and spatial variability, the modeling of groundwater fluctuations is a very difficult task. Over the past decade, tools such as ANN and statistical techniques such as MLR have attracted the attention of some hydrologists and hydrologists for purposes of forecasting / forecasting, due to their parsimony in the data requirement, Simplicity and profitability. Although several studies have been published in the literature that use the MLR as a modeling technique in the field of surface water hydrology [2], the use of the MLR technique in groundwater modeling is very limited in (1978) used the MLR for the simulation of groundwater responses in the Vryburg aquifer in South Africa by considering precipitation and pumping as input parameters. A full review of the application of the ANN to hydrology can be found in the reports of the ASCE Control Committee [3] and in [4]. In the past, several researchers have successfully used ANN for predicting groundwater levels in undefined networks [5 - 12]. Coulibaly et al. [5] have developed four types of ANN models, namely: the input delayed neural network (IDNN), the recurrent neural network (RNN), the radio-resistant basic network (RBF) and the probabilistic neural network (PNN) 
to limit groundwater fluctuations Four observations in the Gondo Aquifer, Burkina Faso, Africa. The depth, precipitation, temperature and water level of the river were used as inputs for the networks, and it was found that the generalized RBF network is not suited to the modeling at the level of the " While IDNN and PNN are effective for predictions up to 2 months ahead. Lallahem et al. [6] developed a feedforward multi-layered network with a standard backpropagation algorithm to estimate soil water levels in 13 piezometers installed in the unconfined limestone aquifer in northern France, Using the monthly variations of fall, temperature and potential evapotranspiration. Daliakopoulos et al. [7] (2005) and Affandi et al. [9] compared different types of back-propagation algorithms to predict fluctuations in water level and found that the ANN model's performance improved from the gradient-progeny algorithm to the Levenberg algorithm -Marquardt, but decreased in the case of the RBF algorithm. Nayak et al. [8] developed feed-forward multi-layer networks, formed with standard back-propagation algorithms, for predicting groundwater level fluctuations at two sites in a shallow confined aquifer of the Central Godavari system Delta, southern India, using different groundwater levels Delays, precipitation and canal flows as inputs to the model. Krishna et al. [10] used feed-forward and RBF networks neural networks, with LevenbergMarquardt training algorithms and Bayesian regularization, to predict water levels one month in advance in six wells installed in A non-confined branch in Andhra Pradesh, southern India. Monthly precipitation, temperature and evapotranspiration were used as inputs, and the neural network feeding with the Levenberg Marquardt algorithm was deemed suitable for predicting water levels in the six wells. Sethi et al. [12] developed feed-forward multilayer networks, with gradient-descent backpropagation algorithms. With the impetus to predict the depths of groundwater in 64 wells dug in the Munijhara micro-basin at Orissa, Similarly, several researchers have used ANN to predict groundwater levels in confined aquifers $[13 ; 14]$, in leaking aquifers $[15 ; 16]$ and in multi-layer aquifers. In recent years, the conjunction of wavelet transformation and ANN techniques has been successfully implemented in hydrological applications [18-24]. The wavelet transform is another technique which can analyze a signal in time and frequency in order to overcome the disadvantages of the conventional Fourier transform. The wavelet transform allows efficient decomposition of time series so that decomposed data can increase the performance of hydrological prediction models by capturing useful information on different resolution levels [22]. Adamowski and Sun [21] proposed a method based on the coupling of discrete wavelet transforms and ANN for flux prediction for non-perennial rivers in semi-arid watersheds. The performance of coupled neural network models (DWT-ANN) was compared to ANN models for flow forecasting. They found that DWT-ANN models provided more accurate flow forecasts than ANN models. Adamowski and Chan [19] proposed a method coupling the discrete wavelet transform and the ANN for the monthly water level forecast underground. By comparing Coupled Coupled Neural Network (DWT-ANN) models with ANN and ARIMA models for groundwater prediction, they found that DWT-ANN models provided more accurate mean predictions of groundwater Models ANN and ARIMA. Adamowski and Prasher [20] compared vector support regression (SVR) and wavelet networks (WN) for daily runoff prediction in a mountainous watershed. They found that the best WN model was slightly better than the best SVR model. Okkan [23] developed a hybrid model using a discrete wavelet transform (DWT) and advanced neural networks (FFNN) for the monthly prediction of runoff. It was found that hybrid models successfully predicted monthly runoff series and gave good predictive performance over conventional methods, including FFNN, multiple linear regression (MLR), combined wavelet-MLR model, and networks Neurons based on PMC. Therefore, the focus of this study was to evaluate the effectiveness of three data-based approaches such as MLR, ANN and DWT-ANNPMC, to predict the spatial-temporal distribution of water levels In a groundwater basin, using relevant actual data. In the present study, the standard modeling protocols MLR, ANN and DWT-ANNPMC were strictly followed and all real world data were considered inputs to the models. The Fez-DRH and Ain Bittit in the Saïss Plain described above. This study demonstrates a scientifically rational methodology for the evaluation of three approaches focused on the data (modeling tools) to simulate groundwater levels using real world data.

\section{Methodology}

\subsection{Wavelet transforms method}

Wavelets are mathematical functions that give a time-scale representation of the time series and their relationships to analyze time series that contain nonstationary. Wavelet analysis allows the use of long time intervals to obtain low frequency information 
and shorter intervals for high frequency information. Wavelet analysis is capable of revealing aspects of data such as trends, breakpoints, and discontinuities that other signal analysis techniques may lack. In addition, it can often compress or denoise a signal.

The basic objective of wavelet transforms is to obtain a complete time-scale representation of localized and transient phenomena occurring at the time scale [25]. An important step in the use of wavelet transforms is the choice of a mother wave (at $\psi$ ).

\subsection{The Discrete Wavelet Transform (DWT)}

As alternative, in prediction applications, the discrete wavelet transform (DWT) is used, due to its simplicity and reduction of computation time. DWT scales and positions are generally based on powers of two (dyadic scales and positions). This is done by modifying the wavelet representation at [26] :

$$
\varphi j, m(m)=\frac{1}{\sqrt{\left|s_{0}^{j}\right|}} \sum_{k} \varphi\left(\frac{k-m \tau_{0} s_{0}^{j}}{s_{0}^{j}}\right) x(k),
$$

Where $\mathrm{j}$ and $\mathrm{m}$ are integers that control size and translation, respectively, while $s O>1$ is a fixed expansion step and $\tau 0$ is a translation factor that depends on the above-mentioned expansion step.

One of the challenges inherent in using DWT for forecasting applications is that if we change the values at the beginning of our time series, then all of the wavelet coefficients will change. To overcome this problem, a redundant algorithm, called a "hole" algorithm, can be used, given by [27]:

$$
C_{i+1}(k)=\sum_{l=-\infty}^{+\infty} h(l) c_{i}\left(k+2^{i} l\right)
$$

Where $\mathrm{h}$ is the low-pass filter and the finest scale is the original time series. To extract the information, Wi $(k)$, which has been eliminated in (Eq. 4), the smoothed version of the signal is subtracted from the coarse signal that preceded it, given by [28]

$$
w_{i}(k)=C_{i-1}(k)-C_{i}(k),
$$

Where ci $(\mathrm{k})$ is the approximation of the signal and $c i-1(k)$ is the coarse signal. Each application of (Eq. 3) and (Eq. 4) creates a smooth approximation and extracts a higher level of detail. Finally, the non-symmetric Haar wavelet can be used as a lowpass filter to prevent future information from being used during decomposition [29].

\begin{tabular}{|c|c|c|}
\hline Models & Input Variables & $\begin{array}{l}\text { Predicted } \\
\text { Variable }\end{array}$ \\
\hline Mod1 & $\begin{array}{l}{[\mathrm{P}(\mathrm{t},), \mathrm{T}(\mathrm{t}), \mathrm{GWL}(\mathrm{t})] ;} \\
{[\mathrm{P}(\mathrm{t}-1), \mathrm{T}(\mathrm{t}-1), \mathrm{GWL}(\mathrm{t}-1)] ;}\end{array}$ & $\mathrm{GWL}(\mathrm{t}+\mathrm{T})$ \\
\hline Mod2 & $\begin{array}{l}{[\mathrm{P}(\mathrm{t},), \mathrm{T}(\mathrm{t}), \mathrm{GWL}(\mathrm{t})] ;} \\
{[\mathrm{P}(\mathrm{t}-1), \mathrm{T}(\mathrm{t}-1), \mathrm{GWL}(\mathrm{t}-1)] ;} \\
{[\mathrm{P}(\mathrm{t}-2), \mathrm{T}(\mathrm{t}-2), \mathrm{GWL}(\mathrm{t}-2)] ;}\end{array}$ & $\mathrm{GWL}(\mathrm{t}+\mathrm{T})$ \\
\hline Mod3 & $\begin{array}{l}{[\mathrm{P}(\mathrm{t},), \mathrm{T}(\mathrm{t}), \mathrm{GWL}(\mathrm{t})] ;} \\
{[\mathrm{P}(\mathrm{t}-1), \mathrm{T}(\mathrm{t}-1), \mathrm{GWL}(\mathrm{t}-1)] ;} \\
{[\mathrm{P}(\mathrm{t}-2), \mathrm{T}(\mathrm{t}-2), \mathrm{GWL}(\mathrm{t}-2)] ;} \\
{[\mathrm{P}(\mathrm{t}-3), \mathrm{T}(\mathrm{t}-3), \mathrm{GWL}(\mathrm{t}-3)] ;}\end{array}$ & $\mathrm{GWL}(\mathrm{t}+\mathrm{T})$ \\
\hline Mod4 & $\begin{array}{l}{[\mathrm{P}(\mathrm{t},), \mathrm{T}(\mathrm{t}), \mathrm{GWL}(\mathrm{t})] ;} \\
{[\mathrm{P}(\mathrm{t}-1), \mathrm{T}(\mathrm{t}-1), \mathrm{GWL}(\mathrm{t}-1)] ;} \\
{[\mathrm{P}(\mathrm{t}-2), \mathrm{T}(\mathrm{t}-2), \mathrm{GWL}(\mathrm{t}-2)] ;} \\
{[\mathrm{P}(\mathrm{t}-3), \mathrm{T}(\mathrm{t}-3), \mathrm{GWL}(\mathrm{t}-3)] ;} \\
{[\mathrm{P}(\mathrm{t}-4), \mathrm{T}(\mathrm{t}-4), \operatorname{GWL}(\mathrm{t}-4)]}\end{array}$ & $\mathrm{GWL}(\mathrm{t}+\mathrm{T})$ \\
\hline
\end{tabular}

Table 1. Models evaluated for the prediction of groundwater level

\subsection{Design of the model}

The first step in designing the model was to choose the input variables. For this, four models were constructed and tested (Table 1), the Mod4 model was retained with respect to its preliminary performances.

\subsection{Comparison of model performance}

\subsubsection{Evaluation of model performance}

The performance of a model derived from a learning method is evaluated by its ability to predict or generalize [30]. Indeed, performance criteria measure the quality or confidence that can be attributed to the results of a forecast, even within a legal framework of certification [31]. The coefficient of determination (R2) (Eq. (5)), the mean square error (RMSE) (Eq. (6)) and the NashSutcliffe (Nash) coefficient (Eq. (7)) were used to compare model performance and choose the best.

$$
\begin{gathered}
R^{2}=1-\frac{\sum_{i=1}^{N}\left(y_{0}-y_{e}\right)^{2}}{\sum_{i=1}^{N}\left(y_{0}-\bar{y}_{0}\right)^{2}} \\
R M S E=\sqrt{\frac{\sum_{i=1}^{N}\left(y_{0}-y_{e}\right)^{2}}{N}} \\
N a s h=1-\frac{\sum_{i=1}^{N}\left(y_{e}-\bar{y}_{e}\right)^{2}}{\sum_{i=1}^{N}\left(y_{0}-\bar{y}_{0}\right)^{2}}
\end{gathered}
$$

Where yo, ye and $\mathrm{N}$ are the SPI values observed, the estimated SPI values and the number of data, respectively. In the efficiency coefficient of the model of, an efficiency of 1 corresponds to a perfect 


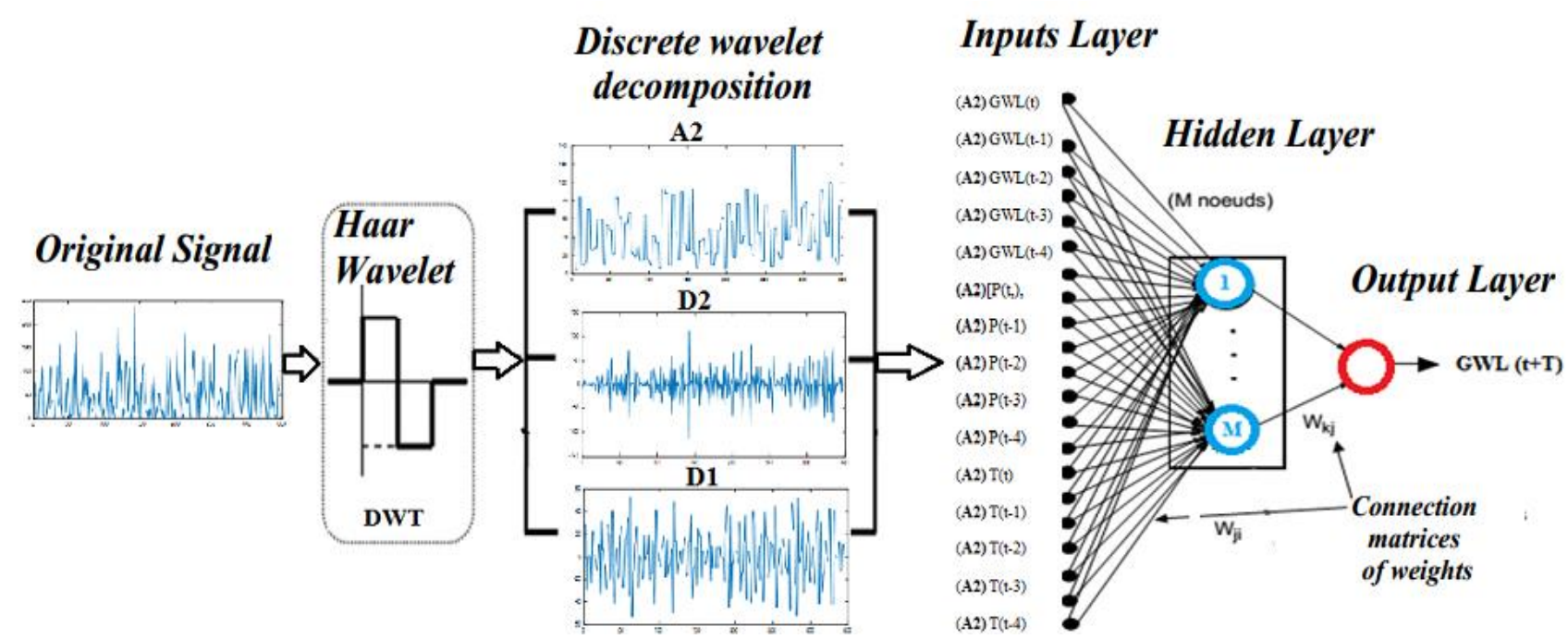

Figure.1 Architecture of the DWT-ANN-PMC 3 model selected for the GWL forecast at the two stations Fez-DRH and Ain Bittit

correspondence of the predicted data with the observed data.

\subsection{Data collection}

The PMC-ANN and Model DWT-ANN-PMC in this study were developed using hydrological and meteorological variables. Specifically, the data used in this study consisted of total monthly precipitation $(\mathrm{mm})$, mean monthly temperature $\left({ }^{\circ} \mathrm{C}\right)$, and average monthly groundwater levels $(\mathrm{mm})$.

\subsection{Development of models}

\subsubsection{The model of artificial neural networks (ANN-} PMC)

For the model architecture based on the Artificial Neural Network (ANN-PMC), simple three-layer architecture was chosen since it was found that a three-layer model is sufficient for prediction and simulation in the field of water sciences [31]. ANN-PMC models were formed and evaluated on the basis of different combinations of time series and the number of neurons in the hidden layer of the model. The input parameters consisted of various combinations of the following physical variables: mean monthly temperature $(\mathrm{T})$, monthly precipitation total $(\mathrm{P})$, and monthly groundwater average (GWL). The various combinations of these variables of the current month $(\mathrm{t})$, from 1 month before ( $\mathrm{t}-1)$, from 2 months before $(\mathrm{t}-2)$, from 3 months before ( $\mathrm{t}-3)$ and from 4 months before $(\mathrm{t}-4)$ were tested. The models were then compared using statistical measures of the quality of the fit described previously. For the ANN-PMC models, the data series were divided into a learning series (November
2002 to June 2008), a validation part (July 2008 to February 2009), and another part for model testing (March 2009 to October 2009).

\subsubsection{Model DWT-ANN-PMC}

The DWT-ANN-PMC models are the ANNPMC models that use, as inputs, sub-components of the series (DWs), which are derived from the DWTs of the original time series data. As already mentioned, the DWT was used in this study because it requires less computational effort than the CWT. One of the advantages of the DWT-ANN-PMC method compared to the ANN-PMC method is its ability to identify data components in a time series as irregular components with multi-level wavelet decomposition [30].

\subsubsection{Wavelet decomposition}

In the proposed model DWT-ANN-PMC, the database variables for each rainfall station and the two piezometers were broken down into subsets of approximations and details (DWS). The process consists of a number of successive steps of filtering. The original series of the database are first decomposed into an approximation and accompanying detail signal. The decomposition process is then iterated, with successive approximation signals being decomposed in turn.

As a result, the original series of the database are broken down into several low-resolution components. When performing wavelet analyzes, the number of decomposition levels that is appropriate for the data must be chosen. A method commonly used to determine the number of 
Table 2. Different combinations of DWT-ANN-PMC models tested for GWL prediction

\begin{tabular}{|c|c|c|}
\hline Models tested & Inputs Variables & $\begin{array}{l}\text { Predicted } \\
\text { element }\end{array}$ \\
\hline DWT-ANN-PMC1 & $\begin{array}{l}\text { (D2) }[\mathrm{P}(\mathrm{t},), \mathrm{T}(\mathrm{t}), \mathrm{GWL}(\mathrm{t})] ; \text { (A2) }[\mathrm{P}(\mathrm{t},), \mathrm{T}(\mathrm{t}), \mathrm{GWL}(\mathrm{t})] ; \\
\text { (D2) }[\mathrm{P}(\mathrm{t}-1), \mathrm{T}(\mathrm{t}-1), \mathrm{GWL}(\mathrm{t}-1)] ;(\mathrm{A} 2)[\mathrm{P}(\mathrm{t}-1), \mathrm{T}(\mathrm{t}-1), \mathrm{GWL}(\mathrm{t}-1)] ; \\
\text { (D2) }[\mathrm{P}(\mathrm{t}-2), \mathrm{T}(\mathrm{t}-2), \mathrm{GWL}(\mathrm{t}-2)] ;(\mathrm{A} 2)[\mathrm{P}(\mathrm{t}-2), \mathrm{T}(\mathrm{t}-2), \mathrm{GWL}(\mathrm{t}-2)] \\
\text { (D2) }[\mathrm{P}(\mathrm{t}-3), \mathrm{T}(\mathrm{t}-3), \mathrm{GWL}(\mathrm{t}-3)] ;(\mathrm{A} 2)[\mathrm{P}(\mathrm{t}-3), \mathrm{T}(\mathrm{t}-3), \mathrm{GWL}(\mathrm{t}-3)] ; \\
\text { (D2) }[\mathrm{P}(\mathrm{t}-4), \mathrm{T}(\mathrm{t}-4), \mathrm{GWL}(\mathrm{t}-4)] ;(\mathrm{A} 2)[\mathrm{P}(\mathrm{t}-4), \mathrm{T}(\mathrm{t}-4), \mathrm{GWL}(\mathrm{t}-4)]\end{array}$ & $\mathrm{GWL}(\mathrm{t}+\mathrm{T})$ \\
\hline DWT-ANN-PMC2 & 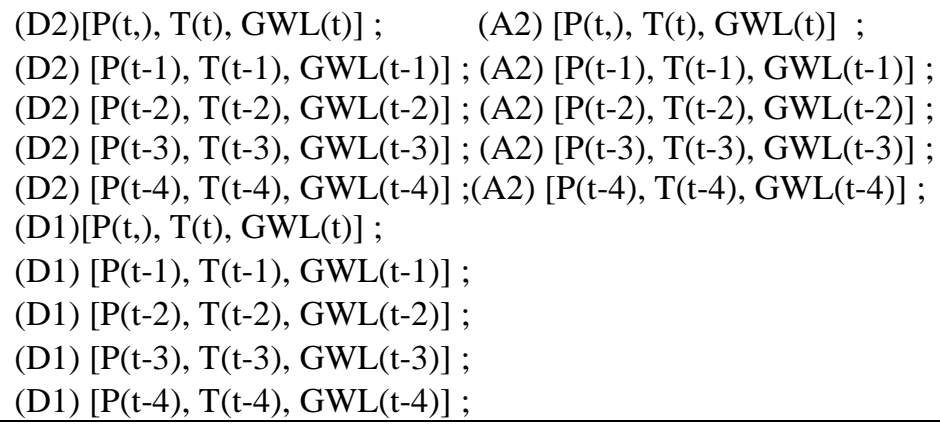 & $\mathrm{GWL}(\mathrm{t}+\mathrm{T})$ \\
\hline DWT-ANN-PMC3 & $\begin{array}{l}\text { (A2) [P(t), T(t), GWL(t)]; } \\
\text { (A2)[P(t-1), T(t-1), GWL(t-1)]; } \\
(\mathrm{A} 2)[\mathrm{P}(\mathrm{t}-2), \mathrm{T}(\mathrm{t}-2), \mathrm{GWL}(\mathrm{t}-2)] ; \\
(\mathrm{A} 2)[\mathrm{P}(\mathrm{t}-3), \mathrm{T}(\mathrm{t}-3), \mathrm{GWL}(\mathrm{t}-3)] ;(\mathrm{A} 2)[\mathrm{P}(\mathrm{t}-4), \mathrm{T}(\mathrm{t}-4), \mathrm{GWL}(\mathrm{t}-4)]\end{array}$ & $\mathrm{GWL}(\mathrm{t}+\mathrm{T})$ \\
\hline
\end{tabular}

decomposition levels is based on the signal length [32] and is given by $\mathrm{L}=$ int $[\log (\mathrm{N})]$, where $\mathrm{L}$ is the decomposition level and $\mathrm{N}$ is the length of the signal.

Some DWT-ANN-PMC models have been evaluated (Table 2). The DWT-ANN-PMC 3 model was selected for its preliminary performance.

The training in this study comprised between 380 and 432 samples (samples varied according to the number of entries for each weather station). Thus, the rate of decomposition was selected as $\mathrm{L}=$ 2. As discussed in the previous section the "a hole" wavelet algorithm with a Haar low-pass filter was used to create four sets of subseries d Wavelets. These three subsets include a low frequency component (the approximation) used to uncover the trend of each signal and two high frequency components (the details) used to uncover the periodicity of the signal.

All decomposed subseries have been added together to generate a time series and used as input for the DWT-ANN-PMC model. Using the sum of all sub-series as an entry in this study yielded more accurate results than the use of certain sub-series or subseries that had the strongest correlations with the original time series.

In this research, DW1 and DW2, as well as the approximate series, were summed and used as inputs in ANN-PMC models. For the DWT-ANN-PMC model, the ANN-PMC networks that were developed consisted of an input layer, a single hidden layer, and an output layer comprising a corresponding node at the level of the DWT- underground water. Input nodes consisted of various combinations of the following variables: the DW series sum (and approximate series) of mean temperature, total precipitation, and the average of the groundwater level (current month, The previous month, ranging from 2 months before, 3 months before and 4 months before). As with the ANNPMCs Regular Force, each model was tested on a trial and error basis to determine the optimal number of hidden layer neurons based on different combinations of variables in the input layer of the model and the number of neurons in the hidden layer of the model. The optimal number of neurons was found to be 2 for all models. For the DWTANN-PMC model, data series were divided into a learning series (November 2002 to June 2008), (July 2008 to February 2009) for validation, and the series (March 2009 to October 2009) for Test the model.

\subsection{Comparison with the multiple linear regression model (MLR)}

To evaluate the performance of the DWT-ANNPMC model, a comparison with other more classical models, essentially the multiple linear regression (MLR) model, was used. The application of this model was made on the same sets of data used in the neural method for the two phases of modeling.

The MLR model for groundwater level prediction for the two study sites was developed using statistica software [33]. Multiple linear regression (MLR) is a generalization of the simple regression model when the explanatory variables are 
finite. It consists in finding a linear equation linking the variable to be modeled (variable to be explained or endogenous) to the matrix of inputs or (explanatory or exogenous variables). The specific MLR models were developed using variables (total monthly precipitation, monthly mean temperature and groundwater levels) as independent variables, and groundwater levels in the two study sites as dependent variables. A total of $70 \%$ of the data covering the period 1980-2014 was used for training and $30 \%$ of the data (for the period 2003-2004) were used for the tests.

For the first modeling step, we took the set of data used during the learning and testing of the ANN-PMC model for the application of multiple linear regressions.

For the second modeling step, the inputs variables are:

[P(t), T (t), GWL (t)];

[P(t-1), T (t-1), GWL (t-1)];

[P (t-2), T (t-2), GWL (t-2)];

[P (t-3), T (t-3), GWL (t-3)];

[P (t-4), T (t-4), GWL (t-4)],

The output variable is GWL $(t+1)$.

Fig. 2 shows the comparison between the predicted and observed GWLs for the validation phase for successive forecast periods at $t+1, t+2$ and $\mathrm{t}+3$. By increasing the prediction time $(\mathrm{t}+1, \mathrm{t}$ +2 to $t+3$ ), the coefficient of determination $R^{2}$ is reduced between the observed and the estimated values and an increase in the MAE and RMSE errors. Consequently, a scattering of the cloud of points around the curve is noted which indicates a decrease in the correlation between the predicted GWL values and those observed. The model becomes divergent by accumulation of forecast errors by lengthening the forecasting time.

\section{Results and discussion}

For the two study sites (Fez-DRH and Ain Bittit), the DWT-ANN-PMC models proved their best performance with more accurate and accurate results for groundwater level prediction than ANN-PMC models and Models during the different time scales (1 month, 2 months and 3 months).

For both study sites, the best DWT-ANN-PMC models were based on variables such as total precipitation for the current month, the previous month 2, 3, and 4 months before; The average temperature of the current month, the previous month 2, 3, and 4 months before; And the average level of groundwater from the current month the previous month 2,3 , and 4 months before.

The best DWT-ANN-PMC models for both study sites had 10 neurons in the hidden layer. For both study sites, the best ANN model had the same variables as the best DWT-ANN-PMC model for both sites. The best models for ANN and MLR for the two sites had respectively 10 and 15 neurons in the hidden layer.

The best DWT-ANN-PMC models for the FezDRH and Ain Bittit sites had a RMSE test of $0.04 \mathrm{~m}$ and $0.09 \mathrm{~m}$ respectively and were superior to the best ANN model and the MLR model, which had a test RMSE of $0.309 \mathrm{~m}$ and $0.321 \mathrm{~m}$ for the FezDRH site and $\mathrm{m}$ and $0.3380 .370 \mathrm{~m}$ for the Ain Bittit site. Lower RMSE values (with 0 being a perfect fit value) indicate that the best DWT-ANN-PMC model had smaller differences and differences between the predicted groundwater level and the groundwater levels observed over the two Sights in La Saïss Plain.

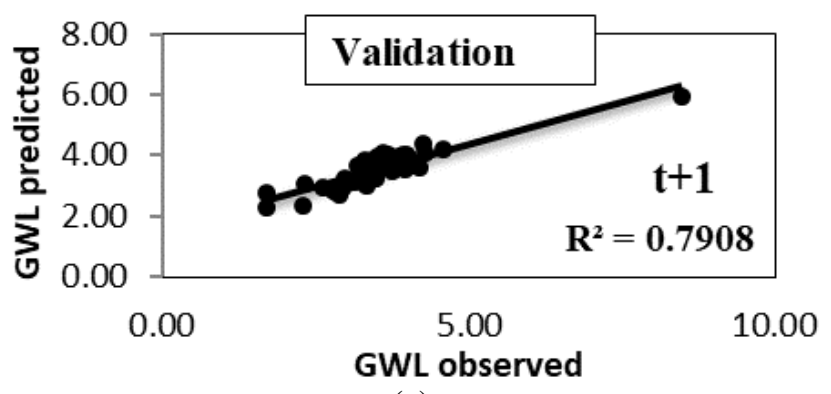

(a)

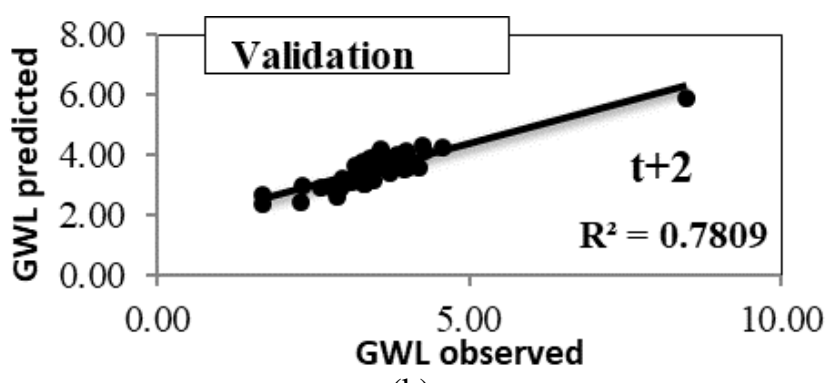

(b)

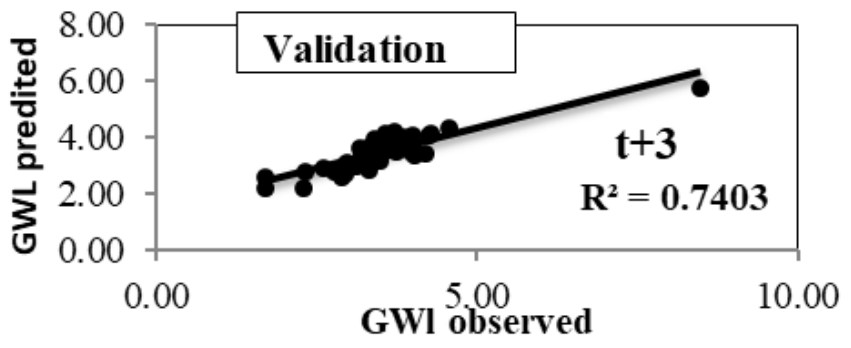

(c)

Figure. 2 Comparisons between the predicted GWL $\mathrm{t}$ observed for the validation phase of the MLR model at the Fez-DRH site: (a) $t+1$, (b) $t+2$, and (c) $t+3$ 
Table 3. Comparison of the best results of the ANN-PMC, DWT-ANN-PMC and MLR models for the prediction of the groundwater level for 1 month at the two stations Fez-DRH and Ain Bittit during the period 1980-2014

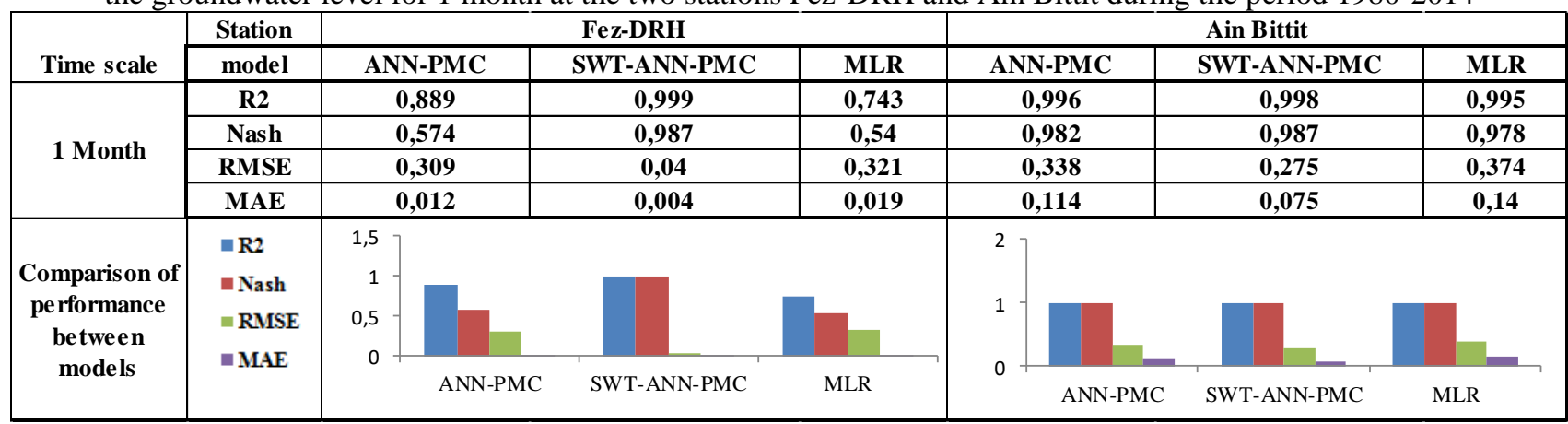

Table 4. Comparison of the best results of the ANN-PMC, DWT-ANN-PMC and MLR models for the prediction of the groundwater level for 2 months at the two stations Fez-DRH and Ain Bittit during the period 1980-2014

\begin{tabular}{|c|c|c|c|c|c|c|c|}
\hline \multirow[b]{2}{*}{ Time scale } & \multirow{2}{*}{$\begin{array}{l}\text { Station } \\
\text { Model }\end{array}$} & \multicolumn{3}{|c|}{ Fez-DRH } & \multicolumn{3}{|c|}{ Ain Bittit } \\
\hline & & model-ANN-PMC & model-SWT-ANN-PMC & model-RLM & model-ANN-PMC & model-SWT-ANN & model-RLM \\
\hline \multirow{4}{*}{2 Months } & R2 & 0,851 & 0,981 & 0,759 & 0,995 & 0,996 & 0,995 \\
\hline & Nash & 0,46 & 0,967 & 0,323 & 0,978 & 0,983 & 0,979 \\
\hline & RMSE & 0,764 & 0,128 & 0,834 & 0,383 & 0,09 & $\mathbf{0 , 3 7}$ \\
\hline & MAE & 0,277 & 0,006 & 0,153 & 0,146 & 0,008 & 0,137 \\
\hline $\begin{array}{c}\text { Comparison of } \\
\text { performance } \\
\text { between } \\
\text { models }\end{array}$ & $\begin{array}{l}\| \mathrm{R} 2 \\
\text { "Nash } \\
=\mathrm{RMSE} \\
\text { "MAE }\end{array}$ & $\begin{array}{r}1,5 \\
1 \\
0,5 \\
0\end{array}$ & SWT-ANN-PMC & MLR & $\begin{array}{r}1,5 \\
1 \\
0,5 \\
0\end{array}$ & SWT-ANN-PMC & MLR \\
\hline
\end{tabular}

Table 5. Comparison of the best results of the ANN-PMC, DWT-ANN-PMC and MLR models for the prediction of the groundwater level for 3 months at the two stations Fez-DRH and Ain Bittit during the period 1980-2014

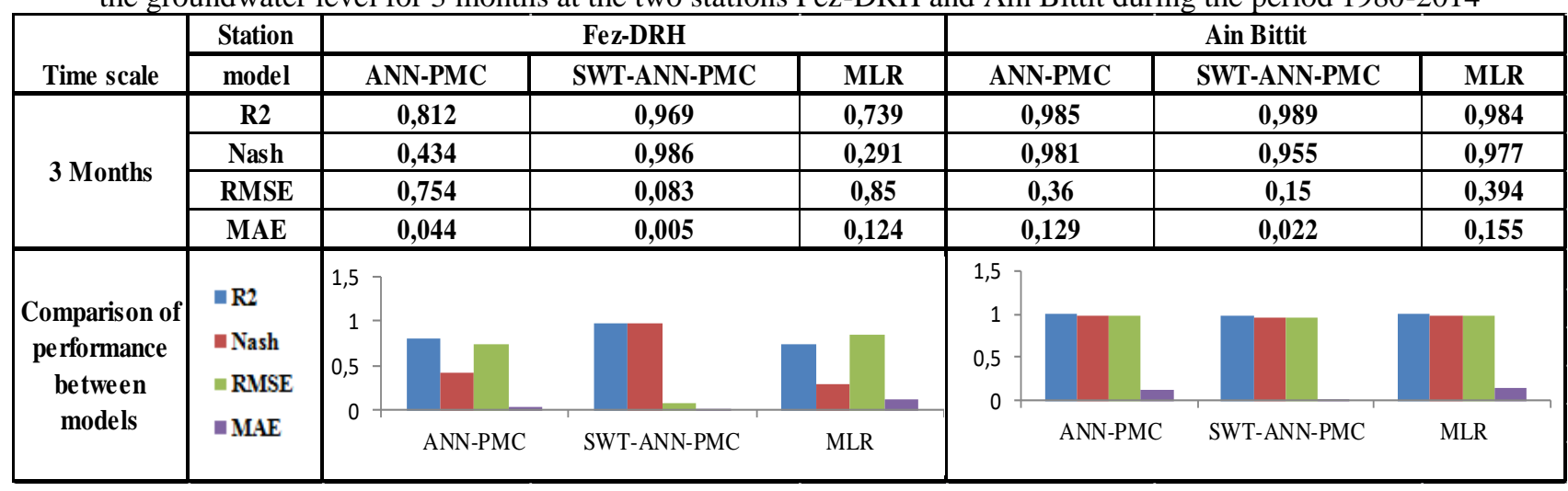

The best DWT-ANN-PMC models for the FezDRH and Ain Bittit sites had an $\mathrm{R}^{2}$ test of 0.999 and 0.998, respectively and were superior to the best ANN and MLR models, which had an R2 0.889 and 0.759 for the Fez-DRH site and 0.996 and 0.995 for the Ain Bittit site. The best DWT-ANN-PMC models for the Fez-DRH and Ain Bittit sites had an Nash-test of 0.987 and 0.986 , respectively and were superior to the best ANN model and the MLR model, which had An Nash-test of 0.574 and 0.540 for the Fez-DRH site and 0.982 and 0.979 for the Ain Bittit site. The values of $\mathrm{R}^{2}$ and Nash indicate the superiority of the DWT-ANN-PMC model compared to other models.
The tables 3, 4 and 5 show too the comparison of the correlation coefficients between the observed values and the estimated values obtained by the two forecast models ANN and MLR. The correlation coefficients indicate the best performance and convergence of the neural network model with respect to the multiple regressions.

The advantage of the neural network is that on the basis of the exogenous variables one can calculate several endogenous variables whereas the multiple linear regressions makes it possible to calculate only one endogenous variable at a time.

Modeling by artificial neural networks indicates 
Table.6 Comparisons of the predicted GWL and GWL values observed for 1 month ahead at the two Fez-DRH and Ain Bittit stations by the three ANN-PMC, DWT-ANN-PMC and MLR model

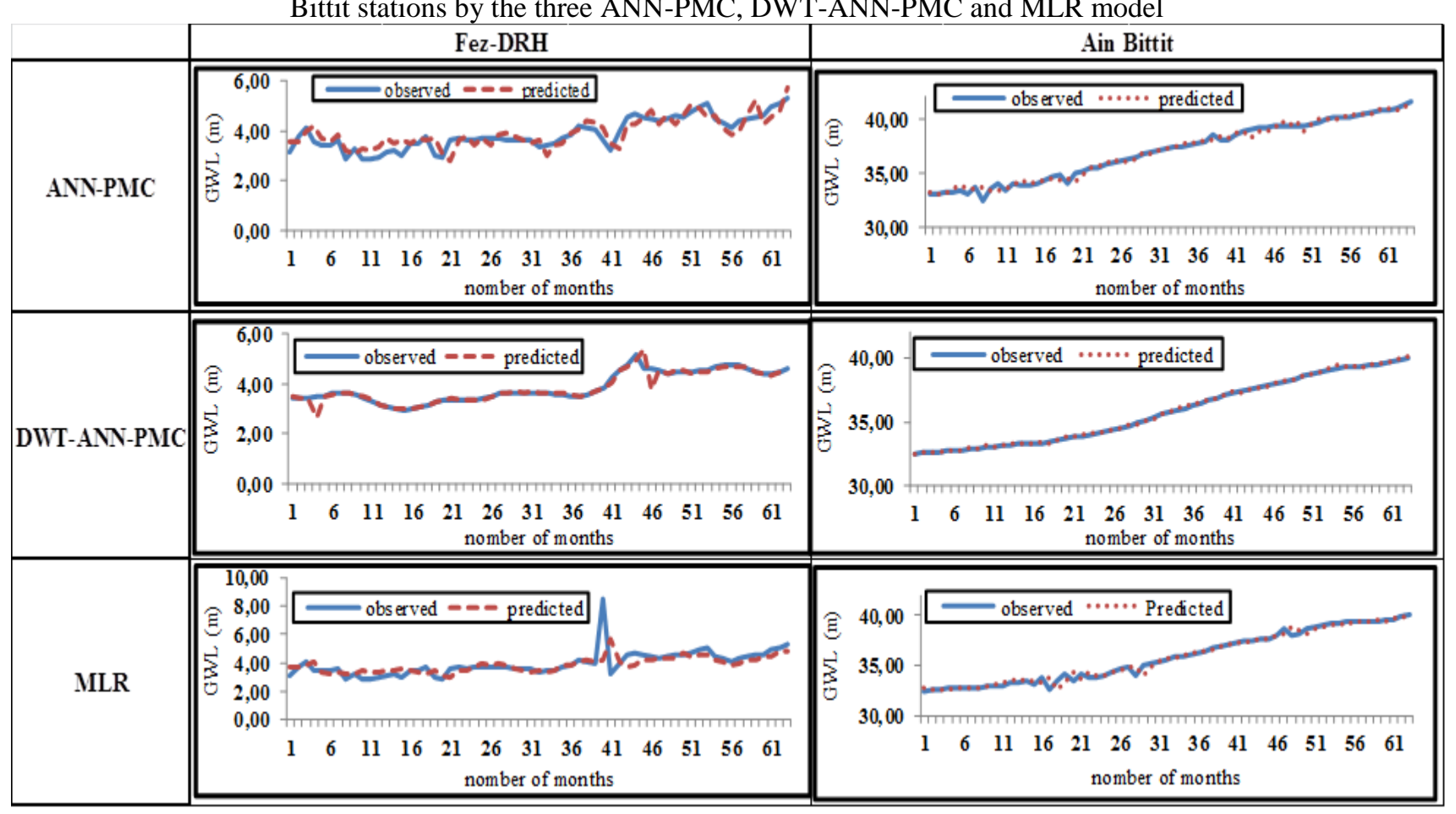

a good correlation between the observed values and the estimated values. As a result, the ANN model has better predictive power compared to conventional models such as MLR.

The comparison of the groundwater level observed with the groundwater level predicted during the trial period at the two sites Fez-DRH and Ain Bittit for the best models DWT-ANN-PMC, ANN-PMC and MLR respectively (Table 3, 4 and 5), Shows that the best ANN-PMC model and the best MLR model tend to over-forecast the groundwater level for both stations, while the DWTANN-PMC model provides estimates closer to the Groundwater observed corresponding.

The Fig. 6 and the table 7 of dispersion diagrams comparing observed and predicted groundwater level values based on the DWT-ANN-PMC, ANNPMC and MLR models for 1 month ahead of the test period on both Sites Fez-DRH and Ain Bittit.

It is clear that the DWT-ANN-PMC model has less dispersed estimates and that values are denser in the vicinity of the straight line than the ANN-PMC model and the MLR model. Overall, the best DWTANN-PMC model at the two study sites yielded more accurate forecasting results than the best ANN-PMC model and the best MLR model for water level prediction underground with a delay of 1 month in advance.

\section{Conclusions}

In this research, a new method based on the coupling of discrete wavelet transform (DWT) and artificial neural networks (ANN-PMC) for groundwater level prediction applications has been proposed to help managers plan Watershed management and to manage the supply of groundwater in a more efficient and sustainable way. DWT-ANN-PMC models were compared to regular ANN-PMC models and MLR models for average groundwater level predictions for different time scales of 1, 2 and 3 months at two Fes-DRH and Ain sites Bittit in the Plain of Saïss.

The hybrid models of DWT-ANN-PMC was developed by the combination of two methods, namely discrete wavelet transform and artificial neural networks. Using the discrete wavelet transform, each of the original data series was broken down into a component series that carried out most of the information, which was then used in prediction through artificial neural networks.

The discrete wavelet transform allowed most "noisy" data to be eliminated and facilitates the extraction of quasi-periodic and periodic signals in the original data time series. This study revealed that the best DWT-ANN-PMC model was clearly more accurate than the best ANN-PMC model and the best MLR model. It is hypothesized that DWT- 
Table.7 Scatter plots Comparison of observed and predicted GWL values for three models at Ain Bittit during the test and validation period1

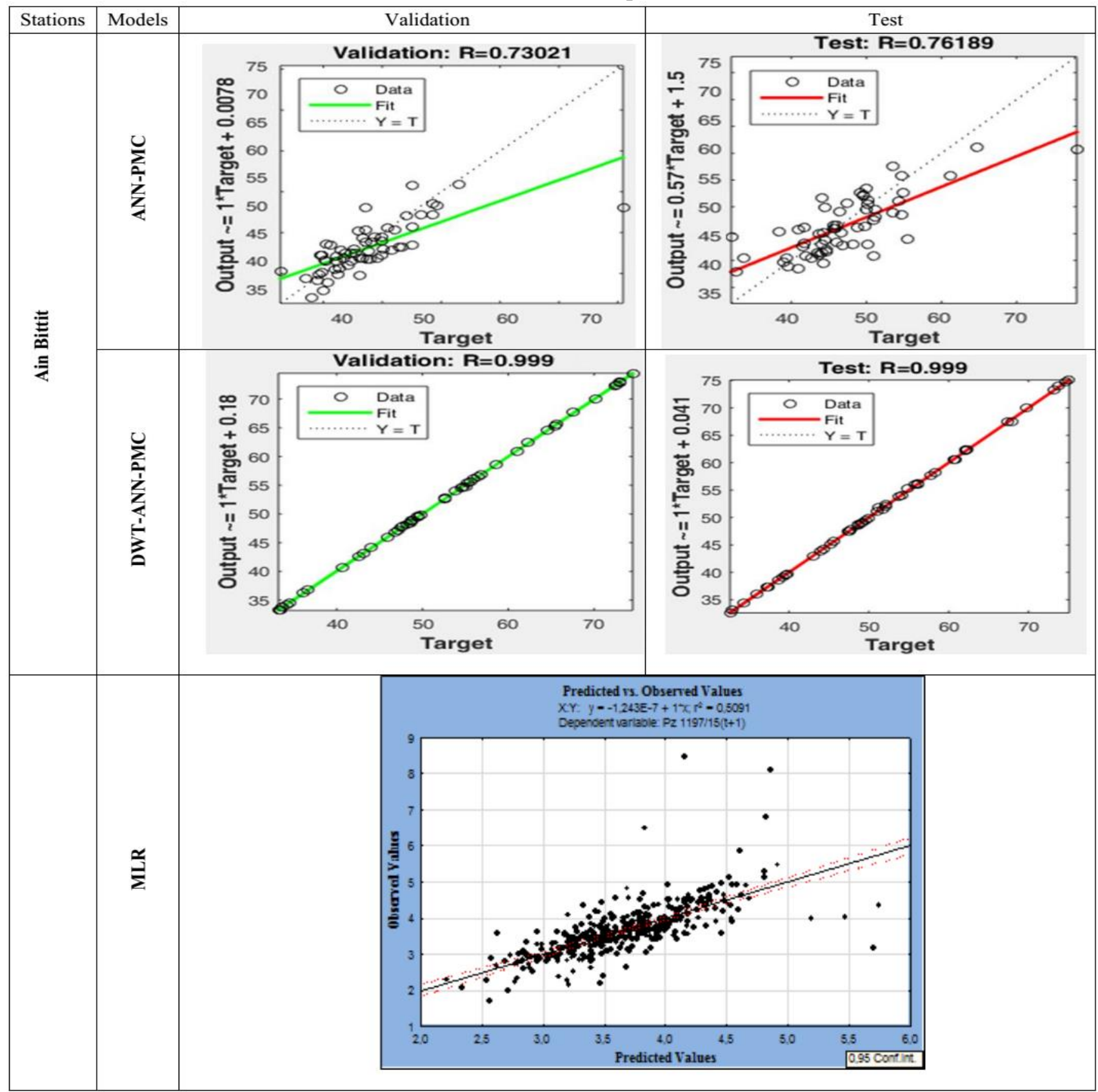

ANN-PMC models are more accurate because wavelet transforms provide useful decompositions of the original time series, and transformed wavelet data improves the performance of the ANN-PMC prediction model by analyzing the useful information on the different levels of decomposition. The results of the precise forecasts for the two Ain Bittit and Fez-DRH sites in the Saïss Plain indicate that the DWT-ANN-PMC method is a potentially very useful new method for predicting the groundwater level.

The very precise groundwater level prediction models such as the DWT-ANN-PMC model developed in this study are useful as very powerful means for predictive management of groundwater resources in semi-arid regions. Of great socioeconomic interest, this ANN model helps decisionmakers make good forecasts of water reserves mainly in the short term. These forecasts may be part of a development project that can be used to provide useful precautions by installing underground dams or lakes, providing for interbasin water transfers or artificial groundwater recharges. 


\section{References}

[1] S. Mohanty, K. Madan, A. Jha, K. Kumar, and P. Sudheer, "Artificial neural network modeling for groundwater level forecasting in a river island of eastern India", Water Resources Management, Vol. 24, No. 9, pp.1845-1865, 2010.

[2] S.K. Sinnakaudan, A.A. Ghani, M.S.S. Ahmad, and N.A. Zakaria, "Multiple linear regression model for total bed material load prediction", $J$. Hydraul Eng. ASCE, Vol. 132, No. 5, pp.521528, 2006.

[3] R.S. Govindaraju, "Artificial neural networks in hydrology, part I: preliminary concepts", $J$. Hydrol. Eng., Vol. 5, No. 2, pp. 115-123, 2000.

[4] H.R. Maier and G.C. Dandy, "Neural networks for the prediction and forecasting of water resources variables: a review of modeling issues and applications", Environ. Modeling Softw., Vol. 15, pp.101-124, 2000.

[5] P. Coulibaly, F. Anctil, R. Aravena, and B. Bobee, "Artificial neural network modeling of water table depth fluctuations", Water Resour. Res., Vol. 37, No. 4, pp. 885-896, 2001.

[6] S. Lallahem, J. Mania, A. Hani, and Y. Najjar, "On the use of neural networks to evaluate groundwater levels in fractured media", $J$. Hydrol. Vol. 307, pp.92-111, 2005.

[7] I.N. Daliakopoulos, P. Coulibaly, and I.K. Tsanis, "Groundwater level forecasting using artificial neural network", J. Hydrol. Vol. 309, pp.229-240, 2005.

[8] P.C. Nayak, Y.R.S. Rao, and K.P. Sudheer, "Groundwater level forecasting in a shallow aquifer using artificial neural network approach", Water Resour. Manag., Vol.20, pp.77-90, 2006.

[9] A.K. Affandi, K. Watanabe, and $\mathrm{H}$. Tirtomihardjo, "Application of an artificial neural network to estimate groundwater level fluctuation" J. Spat. Hydrol., Vol. 7, No.2, pp. 23-46, 2007.

[10] B. Krishna, YRS. Rao, and T. Vijaya, "Modeling groundwater levels in an urban coastal aquifer using artificial neural networks", Hydrol. Processes, Vol. 22, pp.1180-1188, 2008.

[11] I.C. Trichakis, I.K. Nikolos, and G.P. Karatzas, "Optimal selection of artificial neural network parameters for the prediction of a karstic aquifer's response", Hydrol Processes, Vol. 23, pp. 2956-2969, 2009.

[12] R.R. Sethi, A. Kumar, S.P. Sharma, and H.C. Verma, "Prediction of water table depth in a hard rock basin by using artificial neural network", Int. J. Water Resour. Environ. Eng., Vol. 2, No. 4, pp. 95-102, 2010.

[13] A. Hani, S. Lallahem, J. Mania, and L. Djabri, "On the use of finite difference and neuralnetwork models to evaluate the impact of underground water overexploitation", Hydrol. Processes, Vol. 20, pp. 4381-4390, 2006.

[14] V. Uddameri, "Using statistical and artificial neural network models to forecast potentiometric levels at a deep well in South Texas", Environ. Geol., Vol. 51, pp.885-895, 2007.

[15] E.A. Coppola, F. Szidarovszky, M.M. Poulton, and E. Charles, "Artificial neural network approach for predicting transient water levels in a multilayered groundwater system under variable state, pumping, and climate conditions", J. Hydrol. Eng. ASCE, Vol. 8, No. 6, pp. 348360, 2003.

[16] S. Mohanty, M.K. Jha, A. Kumar, and K.P. Sudheer, "Artificial neural network modeling for groundwater level forecasting in a river island of eastern India", Water Resour. Manag., Vol. 24, No.9, pp.1845-1865, 2009.

[17] E.A. Coppola, A.J. Rana, M.M. Poulton, F. Szidarovszky, and V.W. Uhl, "A neural network model for predicting aquifer water level elevations", Ground Water, Vol. 43, No. 2, pp. 231-241, 2005.

[18] R.H. Abiyev, "Fuzzy wavelet neural network based on fuzzy clustering and gradient techniques for time series prediction", Neural Comput. Appl., Vol. 20, No. 2, pp. 249-259, 2011.

[19] J. Adamowski and H.F. Chan, "A wavelet neural network conjunction model for groundwater level forecasting", J. Hydrol. Vol. 407, No. 1, pp. 28-40, 2011.

[20] J. Adamowski and S.O. Prasher, "Comparison of machine learning methods for runoff forecasting in mountainous watersheds with limited data", J. Water Land Dev., Vol. 17, pp. 89-97, 2012.

[21] J. Adamowski and K. Sun, "Development of a coupled wavelet transform and neural network method for flow forecasting of non-perennial rivers in semi-arid watersheds", J. Hydrol. Vol. 390, No. 1, pp. 85-91, 2010.

[22] V. Nourani, M. Parhizkar, T.R. Khanghah, A.H. Baghanam, and E. Sharghi, "Wavelet-based feature extraction of rainfall-runoff process via self-organizing map", In: Proc. of the 12th WSEAS International Conference on Applied 
Computer Science, WSEAS, Greece, pp. 101106, 2012.

[23] U. Okkan, "Using wavelet transform to improve generalization capability of feedforward neural networks in monthly runoff prediction", Sci. Res. Essays., Vol. 7, No. 17, pp. 1690-1703, 2012.

[24] U. Okkan and Z.A. Serbes, "The combined use of wavelet transform and black box models in reservoir inflow modeling", J. Hydrol. Hydromech., Vol. 61, No. 2, pp. 112-119, 2013.

[25] D. Labat, R. Ababou, and A. Mangin, "Rainfall-runoff relations for karstic springs. Part II: Continuous wavelet and discrete orthogonal multiresolution analyses", J. Hydrol., Vol. 238, pp. 149-178, 2000.

[26] T. W. Kim and J. B. Valdes, "Nonlinear model for drought forecasting based on a conjunction of wavelet transforms and neural networks", Journal of Hydrologic Engineering, Vol. 8, No. 6, pp. 319-328, 2003.

[27] J. Adamowski and K. Sun, "Development of a coupled wavelet transform and neural network method for flow forecasting of non-perennial rivers in semi-arid watersheds", Journal of Hydrology, Vol. 390, No. 1-2, pp. 85-91, 2010.

[28] S. G. Mallat, "A Wavelet Tour of Signal Processing“, Academic Press, San Diego, Calif, USA, 1998.

[29] O. Renaud, J. Starck, and F. Murtagh, WaveletBased Forecasting of Short and Long Memory Time Series, Department of Economics, University of Geneve, 2002.

[30] Y. B. Koffi, K.E. Ahossi, A.M. Kouassi, K.L. Christophe, and J. Biemi, "Modélisation de la valeurs en eau potable dans les capitales africaines au sud du Sahara : application des réseaux de neurones formels à la ville de Yamoussoukro, capitale politique de la cote d'ivoire", Journal of Asian Scientific Research 2, Vol. 17, No, 3, pp. 313-328, 2012.

[31] P. Besse, "Data mining II. Modélisation Statistique and Apprentissage "Publications du laboratoire de statistique et probabilités, Université Paul Sabatier, Toulouse, p.103, 2005.

[32] W. Wang and J. Ding, "Wavelet network model and its application to the prediction of hydrology", Nat. Sci. Vol. 1, pp. 67-71, 2003.

[33] M. K. Tiwari and C. Chatterjee, "Development of an accurate and reliable hourly flood forecasting model using wavelet bootstrapANN (WBANN) hybrid approach", Journal of Hydrology, Vol. 394, No. 3-4, pp. 458-470, 2010.
[34] M. Tayyab, J. Zhou, R. Adnan, and X. Zeng, "Application of Artificial Intelligence Method Coupled with Discrete Wavelet Transform Method", Procedia Computer Science, Vol. 107, pp. 212-217, 2017.

[35] S. Chithra, S.R.R.S. Kumar, K. Chinnaraju, and F.A. Ashmita, "A comparative study on the compressive Ashmita, strength prediction models for High Performance Concrete containing nano silica and copper slag using regression analysis and Artificial Neural Networks", Construction and Building Materials, Vol. 114, 528-535, 2016.

[36] B. Yadav and K. Eliza, "A hybrid waveletsupport vector machine model for prediction of Lake water level fluctuations using hydrometeorological data", Measurement, Vol. 103, pp. 294-301, 2017. 